\title{
Health and Disability
}

\section{Satisfaction with life in individuals with a lower limb amputation: The importance of active coping and acceptance}

\author{
M. GRAÇA PEREIRA, ${ }^{1}$ iD CRISTIANA RAMOS, ${ }^{1}$ ARMANDA LOBARINHAS, ${ }^{2}$ J. CUNHA MACHADO ${ }^{3}$ and SUSANA PEDRAS ${ }^{1}$ \\ ${ }^{1}$ School of Psychology, University of Minho, Portugal \\ ${ }^{2}$ School of Social Sciences, University of Minho, Portugal \\ ${ }^{3}$ Physical Medicine and Rehabilitation Department, Hospital of Braga, Portugal
}

Pereira, M. G., Ramos, C., Lobarinhas, A., Machado, J. C. \& Pedras, S. (2018). Satisfaction with life in individuals with a lower limb amputation: The importance of active coping and acceptance. Scandinavian Journal of Psychology, 59, 414-421.

\begin{abstract}
The aim of this study was to analyze the relationship between sociodemographic/clinical characteristics, coping strategies and satisfaction with life in individuals with lower limb amputation. Sixty-three individuals with a lower limb amputation due to Diabetes and Peripheral Vascular Disease participated in the study and answered measures of coping strategies and satisfaction with life. Findings revealed high dissatisfaction with life. Acceptance and active coping were the most used coping strategies. Satisfaction with life was positively associated with active and planning coping, religion, acceptance and humour. There were differences in coping strategies according to gender, age, marital status, presence of residual limb pain, prosthesis use and mobility level. Results emphasize the differential role of coping strategies, for each individual. Psychosocial interventions need to take into consideration coping strategies during the process of rehabilitation and be specific regarding individuals sociodemographic and clinical characteristics. This study may help design interventions that answer individuals with lower limb amputations given that coping strategies are a valuable resource in the promotion of satisfaction with life.
\end{abstract}

Key words: Amputation, coping strategies, satisfaction with life.

M. Graça Pereira, School of Psychology, Department of Applied Psychology, University of Minho, 4710-245 Braga, Portugal. E-mail: gracep@psi.uminho.pt

\section{INTRODUCTION}

The most common causes of amputation are vascular diseases, trauma, malignancy, and congenital deficiency. Amputation rates have increased among cardiovascular patients, declined in individuals with trauma, and remained unchanged in patients with cancer and congenital amputations (Varma, Stineman \& Dillingham, 2014). Amputations due to Diabetic Foot Ulcer (DFU), a diabetes-related complication, and Peripheral Vascular Disease (PVD) are therefore responsible for about $40-70 \%$ of all amputations performed by non-traumatic causes (International Working Group on the Diabetic Foot, 2007; Ramsey, Newton, Blough et al., 1999; Unwin, 2000). Traumatic amputations are frequently associated with an increased use of a prosthesis, while patients with an amputation due to DFU/PVD have less mobility, more morbidities and are less likely to use a prosthesis (Sansam, Neumann, O'Connor \& Bhakta, 2009). In Portugal, there is no data about the number of amputations, except the amputations due to DFU/PVD, which in 2015, accounted for 1,643 hospital admissions and 1,250 amputations (545 major and 705 minor) (Portuguese Society of Diabetes, 2016). Consequently, a lower limb amputation (LLA) causes mobility difficulties and changes in the individuals' functionality, daily life, work and social interactions. Individuals with LLA have to adapt to a new lifestyle and often restrict leisure activities due to the physical and interpersonal obstacles; as well as the activities carried out at home (Amtmann, Morgan, Kim \& Hafner, 2015). Individuals with higher mobility impairment are more likely to report lower life satisfaction (Blace, 2012).
Coping is as a psychological strategy mobilized to decrease, modify, or diffuse the impact of stress caused by life events (Lazarus \& Folkman, 1984). Coping strategies may have an effect on satisfaction with life in amputees depending on their effectiveness regarding problem resolution. Thus, according to the literature, adopting a positive reinterpretation towards the amputation is a more favourable coping strategy towards one's health and physical capacity, associated with a lower level of restriction in physical activities and a greater adjustment to amputation (Andersson \& Deighan, 2006; Couture, Desrosiers \& Caron, 2011, 2012; Gallagher \& Maclachlan, 2000, 2001). Active/ task-oriented strategies such as problem solving were associated with positive psychosocial adjustment and acceptance of disability (Dunn, 1996; Livneh, Antonak \& Gerhardt, 1999) and negatively with depression and internalised anger (Livneh et al., 1999). In fact, problem-focused coping strategies were found to be significant predictors of posttraumatic growth in a sample of war veterans amputees (Tuncay \& Musabak, 2015). In turn, emotion focused strategies such as avoidance and catastrophizing have been associated with a worse psychosocial adjustment and more symptoms of depression and anxiety, hostility and lack of acceptance of the problem, in individuals with LLA (Andersson \& Deighan, 2006; Couture et al., 2011, 2012; Desmond, 2007; Gallagher \& Maclachlan, 2000). The use of cognitive disengagement has been associated with poor psychosocial outcomes, with depression, externalised hostility and lack of acceptance of disability (Hill, Niven \& Knussen, 1995; Livneh et al., 1999). Wegener, Mackenzie, Ephraim, Ehde and Williams (2009), in a clinical trial of a self-management intervention to 
improve outcomes after limb loss concluded that coping skills training was a central component of intervention in this population.

In addition, the residual limb pain (RLP) and the phantom limb pain (PLP) have been described as quite prevalent. RLP is an acute nociceptive pain and usually disappears a few weeks after the amputation, when the wound is already healed (Aronow, 2007; Neil, 2015). On the other hand, PLP is the perception of pain in the part of the body, after its removal (Foell \& Flor, 2011; Jackson \& Simpson, 2004). Both types of pain may have a deteriorating effect on the mental and physical well-being, affecting the overall satisfaction with life. The experience of pain along with mobility difficulties may predispose individuals to be less satisfied with their life.

Several factors influence satisfaction with life in individuals with a chronic illness or/and disability, including the following: sociodemographic (e.g. gender, education, age, marital status) and disability-related factors (e.g., level of functional limitations, age at onset of disability, duration of condition) (Ostile, Magnus, Skjeldal, Garfelt \& Tambs, 2010; Sinha \& van den Heuvel, 2011). Since, these factors are unchangeable, there is a need to develop coping strategies to meet individuals' needs. However, there is little information regarding the relationship between different coping strategies and satisfaction with life, as well as which sociodemographic and clinical variables influence the use of specific coping strategies over others, in this population.

According to the Organization for Economic Co-operation and Development Guidelines (Eurofound, 2012), subjective well-being should be measured through three distinct but complementary sub-dimensions: life satisfaction, affection and eudaimonia. This study focuses on satisfaction with life that is based on a general cognitive evaluation, considered the most stable of the three previous components, but it is considered a subjective dimension that cannot be objectively evaluated. According to Diener, Emmons, Larsen and Griffiin (1985), well-known researchers in the field, satisfaction with life is one of the indicators of "apparent" quality of life, among other physical and mental indicators, consisting of the global evaluation of feelings and attitudes about life itself at a given moment, ranging from negative to positive aspects. Satisfaction with life has been also defined as the difference between one's own assumptions and plans, and real achievements (Bowling, 1997).

Satisfaction with life is an important predictor of quality of life that may be promoted in psychosocial intervention programs for individuals with an amputation. Amputees' quality of life has been described as poor when compared to the general population and controls (Amtmann et al., 2015; Kohler, Tomlinson, Chilunjika, Young, Hosseinipour \& Lee, 2017; Remes, Isoaho, Vahlberg, Viitanen, Koskenvuo \& Rautava, 2010; Sinha \& van den Heuvel, 2011; Sinha, van den Heuvel \& Arokiasamy, 2011) particularly in physical, emotional and social dimensions, as well as pain, as opposed to mental health and vitality dimensions, and general health (Kohler, et al., 2017; Quigley \& Dillon, 2014). In a study of Portuguese amputees, in which the duration of amputation was one year, Dias (2006) found that amputees were moderately satisfied with their lives and found significant and positive relationships between life satisfaction and the health status domains (such as, physical functioning, general health, social function, vitality, emotional functioning and mental health).
Few studies analysed the relationship between coping strategies and satisfaction with life, in amputees. Effective coping strategies are one of the most important predictors of well being across the life span (Dubey \& Agarwal, 2007), being the use of planning, reinterpretation of the event, active confronting of the problem and growing while facing the problem, a way to improve satisfaction with life, especially in chronically ill patients (Dubey \& Agarwal, 2007). However, which coping strategies are most effective in promoting satisfaction with life in amputees, is still lacking consensus. In addition, most studies focused on the role of coping as a contributor to psychosocial adjustment to amputation (Desmond \& MacLachlan, 2006a; Livneh et al., 1999) but not regarding satisfaction with life, which is an important factor not only for overall quality of life but also for psychosocial adjustment. Furthermore, those studies included only patients with traumatic or acquired amputations (Desmond \& MacLachlan, 2006b) or due to PVD (Couture et al., 2011), not allowing for a comparison between groups according to the cause of amputation and an amputation due to an accident is quite different than an amputation due to a chronic illness, such as Diabetes.

Based on the theoretical framework of Psychosocial Adaptation to Chronic Illness and Disability (CID) (Livneh \& Antonak, 1997), coping strategies play different roles regarding, satisfaction with life. Therefore, taking into account the antecedents (sociodemographic and clinical variables) as well as the disabilityrelated factors, this study's aims were: (1) to characterize and evaluate the relationship between coping strategies and satisfaction with life; and (2) to analyze the differences in coping strategies and satisfaction with life according to the sociodemographic and clinical variables. We hypothesized that the use of active coping strategies would be positively associated with the perception of satisfaction with life and the use of denial and substance use would be negatively associated; the cause (traumatic) and the level of amputation (above-knee), absence of RLP and PLP, prosthesis use and a high mobility level would be associated with satisfaction with life; and finally that demographic characteristics such as age (oldest) and gender (men) would be associated with satisfaction with life.

From an heuristic point of view, it is fundamental to identify high risk individuals in order to develop interventions adapted to their clinical and sociodemographic profile.

\section{METHOD}

\section{Participants and procedures}

The sample included 63 individuals with LLA attending followup consultations in a Physical Medicine and Rehabilitation (PM\&R) department of a major hospital and a Rehabilitation Center, both in northern Portugal. The inclusion criteria were the following: (1) having a LLA; (2) age above 18; and (3) being followed in consultations at the hospital; and the exclusion criteria were: (1) to have a severe psychological or psychiatric disorders (e.g. psychosis recorded in medical records); and (2) acute pain due to traumatic injury besides the amputation. Individuals who met the inclusion criteria were invited by the physiatrist to participate in the study after their routine medical consultation. 
In Portugal, the usual care, after an amputation, involves a referral to a PM\&R unit at the hospital where the individual underwent amputation, but individuals are free to choose the center of rehabilitation (hospital or private clinic) where they wish to do the rehabilitation. Nonetheless, at least every six months, individuals have a follow-up physiatrist's medical appointment in the hospital where they did the surgery and data collection took place at that time. All individuals were invited by their physicians, during a six-month period. Participation was voluntary, involving the signing of an informed form of consent. Participants completed self-report measures in the presence of a health psychologist. The study was approved by the Ethics Committee of both institutions.

\section{Instruments}

Independent variables. The Sociodemographic and Clinical Questionnaire assessed sociodemographic data: age, gender, education, marital and professionals' status and clinical data: cause (trauma, disease, other), level (above and below-knee) and duration of amputation (years), presence of RLP and PLP (yes/ no), prosthesis use (yes/no), and walking ability (no walking ability, walking ability at home/with barriers, walked without limitation).

The Brief COPE Scale (B-COPE, Carver, 1997; Pais-Ribeiro \& Rodrigues, 2004) assesses dispositional coping strategies regarding stressful events and, in this study, individuals were specifically asked to consider coping in strategies to problems associated with their amputation. The instrument consists of 28 items and 14 subscales: Active Coping; Planning Coping; Use of Instrumental Support; Use of Emotional Support; Religion; Positive Reinterpretation; Self-Blame; Acceptance; Expression of Feelings; Denial; Self-distraction; Behavioral Disinvestment; Substance Use and Humor. The answer is given in a Likert scale of 4 points (from " 0 " to " 3 "), ranging from "never do that" to "I always do that." A high score in each subscale indicates greater use of the respective coping strategy. The Cronbach's alphas in this sample only allowed the use of 11 coping subscales: religion (0.74), instrumental support (0.81), planning coping (0.73), active coping (0.79), acceptance (0.98), denial (0.70), emotional support (0.85), expression of feelings (0.78), self-distraction (0.86); substance use (0.66) and humor (0.83). The following coping strategies were not used in the analysis: positive reinterpretation (0.62), self-flame (0.12) and behavioral disinvestment (0.23).

Dependent variable. The Satisfaction with Life Scale (SWLS, Diener et al., 1985; Neto, Barros \& Barros, 1990) assesses the critical judgment that each individual makes about its satisfaction with life. The SWLS consists of 5 items listed on a five-point Likert scale ranging from "strongly disagree" to "strongly agree." A high score indicates greater satisfaction with life. The Cronbach's alpha in the present sample was 0.80 .

\section{Data analysis}

Descriptive statistics (means and standard deviation) and percentages were used to characterize the sample. In order to assess the relationship between coping strategies and satisfaction with life, a Pearson correlation was used, given that the assumptions for the use of parametric statistics were present. To assess the differences in satisfaction with life and coping strategies according to demographic and clinical characteristics Mann-Whitney tests were employed. The following categorical variables were recoded: age (above and below 64 years), marital status (married/single) and employment status (employed versus sick leave, or retired); cause of amputation (trauma versus chronic disease), duration of amputation (above and below the median: bellow 17 and above 18 months) and walking ability (with and without).

\section{RESULTS}

\section{Descriptive data}

Sociodemographic and clinical characterization. The sample consisted of 63 individuals with LLA. The individuals' age ranged from 22 to 89 years, with an average of 63 years ( $\mathrm{SD}=$ 16.3 ) and the majority of individuals were male (79.4\%). Of the total sample, $17.5 \%$ individuals had no education, $65.1 \%$ had four to six years; $12.7 \%$ between $9-12$ years, and $3.2 \%$ had higher education. Most of the individuals (68.3\%) were married or living with a partner, $14.3 \%$ were single and $17.5 \%$ were widowed. Fifty individuals were retired and the remaining were employed, unemployed or in sick leave.

Regarding the cause of amputation, $74.6 \%$ of LLA were the result of a chronic disease (DFU/PVD) and the remaining were due to a trauma. Regarding the amputation level, only $9.5 \%$ of individuals $(\mathrm{n}=6)$ underwent an amputation above-knee. Individuals were amputated for an average of 3.7 years $(\mathrm{SD}=4.2)$ and $56.6 \%$ still reporting RLP and $69.8 \%$ PLP. Of the total sample, $49.2 \%$ individuals used prosthesis for an average of 101.37 months $(\mathrm{SD}=172.1), 46 \%$ had no walking ability, $36.5 \%$ had walking ability at home/with barriers and $17.5 \%$ walked without limitation.

Correlation Analysis. Table 1 shows the descriptive statistics in terms of the mean and standard deviation, as well as minimum and maximum, for satisfaction with life and coping strategies. The mean score on the SWLS (14.06) is indicative of high dissatisfaction with life and, regarding coping strategies, acceptance and active coping were the only strategies that scored above 1 and the lowest score was substance use.

A positive relationship between the use of humor, religion, planning coping, active coping, acceptance, and satisfaction with life was found, as well as a negative relationship between substance use and satisfaction with life (Table 1).

Differences in coping strategies and satisfaction with life according to demographic and clinical variables. There were no differences in satisfaction with life according to sociodemographic characteristics. However, results showed differences in the use of coping strategies according to sociodemographic and clinical characteristics i.e. women showed greater use of denial coping $(U=-2.25, p=0.025), \quad$ younger individuals used more planning coping $(U=-2.14, p=0.033) \quad$ and acceptance $(U=-2.18, p=0.029)$ while those who had a partner showed more expression of feelings $(U=-2.13, p=0.033)$. 


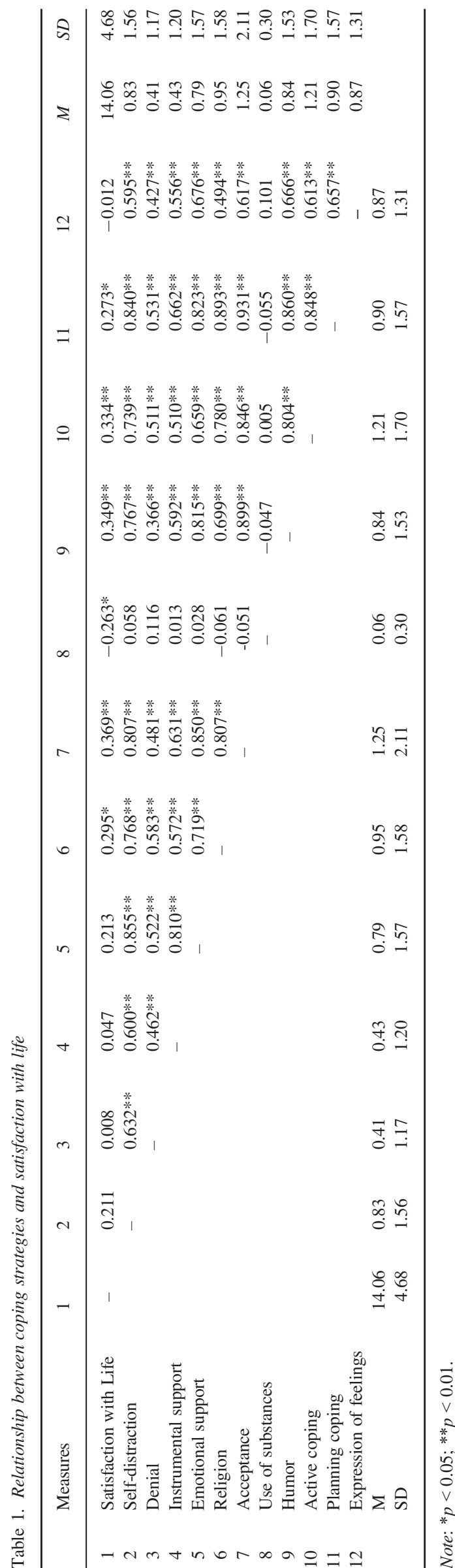

Regarding clinical characteristics, individuals with an above-knee amputation reported lower satisfaction with life $(U=-2.30, p=0.021)$. Results also showed that individuals with RLP used more strategies of coping associated with religion $(U=$ $-1.99, p=0.046)$, active coping $(U=-2.38, p=0.017)$, and self-distraction $(U=-2.02, p=0.043)$. Individuals with prosthesis' use more self-distraction $(U=-1.98, p=0.048)$ and emotional support strategies $(U=-1.96, p=0.050)$. Finally, individuals with high mobility (ability to walk) made more use of coping strategies of self-distraction $(U=-2.17, p=0.030)$, acceptance $\quad(U=-2.27, p=0.023), \quad$ humor $(U=-2.05, p=$ $0.041)$, emotional support $(U=-2.53, p=0.011)$ and active coping $(U=-2.62, p=0.023)$, (Table 2).

\section{DISCUSSION}

The results revealed that individuals were dissatisfied with their life and that acceptance and active coping were the most used coping strategies and the use of substances the less used. In addition, individuals with more satisfaction with life used more active and planning coping, religion, acceptance and humor strategies and less use of substances. Also, individuals with a below-knee amputation were more satisfied with their life and there were differences in coping strategies, according to gender, marital status and age, as well as according to clinical characteristics such as the presence of RLP, mobility and prosthesis use.

In this study, individuals were dissatisfied with their life and this result is not in accordance with the findings of Dias (2006) who, in a Portuguese sample, found that amputees were moderately satisfied with life. Since this sample included individuals who were amputated on average for four years, it was expected that the majority would be adjusted to the amputation, and, consequently, would report greater satisfaction with life. In addition, the cause and duration of amputation had no impact on coping strategies nor in satisfaction with life, which is an interesting result. Probably, the heterogeneity of the sample regarding age, time since amputation and low female representation, may have influenced the results. Therefore, future studies should replicate these results in a more homogeneous sample. However, reality in clinical practice is characterized precisely by this great heterogeneity of individuals and, therefore, efforts must be made for interventions to reach all of them. As satisfaction with life is one of the indicators of "apparent" quality of life (Diener et al., 1985) this should be promoted after amputation, in the rehabilitation process and follow-up consultations in the PM\&R department.

Moreover, satisfaction with life was positively associated with active and planning coping, religion, acceptance and humor. International literature has already documented that coping strategies focused on active resolution are more effective in the decrease of the level of restriction in physical activities and in the adjustment to amputation (Andersson \& Deighan, 2006; Couture et al., 2010; 2012; Desmond, 2007; Gallagher \& Maclachlan, 2000, 2001). Although coping skills training has already proved to be a central component of intervention in this population (Wegener et al., 2009), which coping strategies, in particular, were associated with satisfaction with life, in a sample of 
Table 2. Differences in coping strategies and satisfaction with life according to demographic and clinical characteristics

\begin{tabular}{|c|c|c|c|c|c|c|c|}
\hline Measures & Gender & Age & Marital status & Stump pain & Amputation level & Mobility level & Prosthesis use \\
\hline $\begin{array}{l}\text { Satisfaction with Life } \\
\text { Coping strategies: }\end{array}$ & -.043 & -.248 & -.482 & -.764 & $-2.30 *$ & -0.609 & -0.524 \\
\hline Religion & -1.85 & -0.818 & -0.665 & $-1.99 *$ & -1.01 & -0.146 & -0.115 \\
\hline Instrumental support & -0.027 & -1.19 & -0.464 & -0.348 & -0.734 & -0.976 & -1.30 \\
\hline Planning coping & -0.180 & $-2.14^{*}$ & -0.339 & -1.61 & -1.79 & -1.92 & -1.27 \\
\hline Active coping & -0.194 & -1.88 & -0.818 & $-2.38 *$ & -1.12 & -2.62 & -1.90 \\
\hline Denial & $-2.25^{*}$ & -0.821 & -1.75 & -1.09 & -1.48 & -0.083 & -0.156 \\
\hline Acceptance & -0.152 & $-2.18^{*}$ & -1.17 & -1.33 & -1.83 & $-2.27 *$ & -1.18 \\
\hline Self-distraction & -0.266 & -1.60 & -0.204 & $-2.02 *$ & -0.746 & $-2.17 *$ & $-1.98 *$ \\
\hline Use of substances & -0.898 & -0.577 & -0.040 & -0.806 & -0.192 & -0.411 & -0.577 \\
\hline Emotional support & -0.547 & -1.94 & -0.968 & -1.49 & -1.67 & $-2.53 *$ & $-1.96^{*}$ \\
\hline Expression of feelings & -0.440 & -1.45 & $-2.13^{*}$ & -0.892 & -0.799 & -1.72 & -0.966 \\
\hline Humor & -0.167 & -1.92 & -0.774 & .167 & -1.46 & $-2.05^{*}$ & -1.29 \\
\hline
\end{tabular}

Notes: U- MannWitney Test; *p $<0.05$,

individuals with an amputation due to disease or trauma, was never studied. Therefore, these results reinforce the need to include the training of specific coping skills in psychosocial programs for this population in particular (individuals amputated due to DFU/PVD).

Regarding sociodemographic and clinical characteristics that may be useful in identifying individuals with a higher risk of being dissatisfied with life, the results showed only differences in satisfaction with life, according to the level of amputation. Individuals with amputation above-knee reported less satisfaction with life, as other authors have found (Penn-Barwell, 2011). This result, though not new, emphasizes the need to offer a more structured and intensive support during the rehabilitation process, in the hospital, but also in the community for this group of individuals. Therefore, the objective of identifying characteristics in individuals at high risk of being dissatisfied with life after LLA was partially achieved, since the other sociodemographic and clinical characteristics did not influence satisfaction with life, contrary to our expectations and unlike other studies (Ostile et al., 2010; Sinha \& van den Heuvel, 2011).

With regard to coping strategies, results emphasize that, during the process of adjustment to a new physical condition/limitation, the adopted coping strategies need to take into account the demands imposed by the changes in the physical, psychosocial, spiritual, economic and environmental health of the individual (Dunn, 1996; Livneh \& Antonak, 2005; Livneh \& Wilson, 2003). Literature is consensual regarding the strategies that promote a good adjustment after amputation (Desmond \& MacLachlan, 2006a; Unwin, Kacperek \& Clarke, 2009), such as the adoption of active and planning coping which results in higher levels of functioning and psychological well-being, and the search for instrumental and emotional support (Carver, Scheier \& Weintraub, 1989; Dunne, Coffey, Gallagher \& Desmond, 2014; Livneh \& Antonak, 1997; Livneh et al., 1999; Maes, Leventhal \& Ridder, 1996). On the other hand, the use of emotion focused strategies, such as avoidance and denial was associated with a lower level of functional adjustment to amputation and psychological distress (Carver et al., 1989; Desmond, 2007; Dunne et al., 2014; Livneh \& Antonak, 1997; Livneh et al., 1999). However, in this study, not only problem focused strategies such as planning and active coping (strategies aimed at solving and actively responding to stressful situations) were associated with greater satisfaction with life, but also emotional coping strategies such as acceptance (of a difficult situation and addressing its reality), humor (such as the use of jokes) and religion (using faith in God to seek guidance and support to deal with problems) (Carver et al., 1989; Lazarus \& Folkman, 1984). Taking in consideration the results, one may hypothesize that coping strategies play a differentiated role, for each individual, according to the phase of the adjustment process, since the efficacy of the coping strategy has been reported to be directly related to the context in which it is used (Couture et al., 2010, 2012). For this reason, we believe that the distinction between adaptive and maladaptive coping strategies may be less important than the identification of the diversity of the repertoire of coping strategies used by amputees, with positive results in satisfaction with life.

Taking in consideration the sociodemographic variables, the results showed that women used more denial as a coping strategy. In fact, denial becomes a short-term solution that supports emotion focused coping, however, when used over time it has been associated with higher levels of depression and hostility (Carver et al., 1989; Dunn, 1996). Future studies should clarify this issue, since gender is a known predictor of satisfaction with life and positive outcomes (Kroll, 2011). It is also important for rehabilitation programs, to take into account coping strategies according to gender in order to promote satisfaction with life. Also, younger individuals showed more use of acceptance and planning coping and those who had a partner used more expression of feelings, which makes intuitive sense. However, the use of acceptance as a coping strategy, by younger individuals, was an unexpected result. Age has been shown to impact the acceptance of the limitations imposed by LLA, that is, younger individuals showed less adjustment and acceptance (Carver et al., 1989; Maes et al., 1996). Therefore, one may hypothesize that in this sample, young individuals may be those who had undergone an amputation for traumatic causes and, therefore, needed more time to adapt and accept the situation in comparison to those whose cause of amputation was a chronic illness. In the latter case, patients had more time to adapt while managing their 
chronic illness to avoid another LLA. There were no differences in coping strategies according to the presence or absence of PLP, but there were differences in the use of coping strategies associated with religion, self-distraction and active coping in individuals with RLP. In fact, RLP is perceived as more harmful to one's well-being than PLP, due to the difficulty in prosthesis use that contributes to less physical well-being, negatively impacting the individual's functioning (Aronow, 2007; Neil, 2015). In fact, a coping strategy focused on self-distraction may minimize pain sensitivity (van der Hulst, Vollenbroek-Utten, Schreurs, Rietman \& Hermens, 2010), and reduce physical and psychological suffering (Desmond \& MacLachlan, 2006a) associated with pain, while the active coping strategies are more beneficial in solving problems and helping the individual to resume their daily activities (Livneh et al., 1999). Religion and spirituality have been studied in this population with positive results, not only regarding satisfaction with life, but also general health and social integration (Peirano \& Franz, 2012) and this study is in accordance with these results.

In terms of clinical variables, pain showed no impact on satisfaction with life, contrary to what was expected (Foell \& Flor, 2001; Jackson \& Simpson, 2004) even when more than half of the sample showed PLP and RLP. We believe this result may be related to the elapsed time since the amputation (average of 4 years) and to pain resistance developed by the individual, over time. While some authors report that chronic pain after amputation has a negative impact on one's life, with individuals showing a higher degree of disability compared to those with no pain (Marshall, Helmes \& Deathe, 1992; Neil, 2015), other studies indicate that PLP did not cause major disability in daily living activities (Ehde, Czerniecki, Smith et al., 2001).

Regarding the use of a prosthesis (in this sample, about half used a prosthesis), individuals reported using more self-distraction strategies and planning coping. Since independence may be an issue, planning coping to be able to get around is needed, since walking with a prosthesis requires careful attention (Couture et al., 2012). Self distraction may be a way to avoid negative feelings regarding the amputated member (Sjödahl, Gard \& Jarnlo, 2004).

Finally, individuals with high mobility (ability to walk) reported more acceptance, self-distraction, humor and seeking emotional support. Indeed, the coping strategies such as active and planning coping require choices and preparation/engaging in social activities and goals, along with the use of a prosthesis and the ability to walk, were considered positive predictors of adjustment to amputation (Desmond \& MacLachlan, 2006a). Selfdistraction seems to be a coping strategy used by individuals who use a prosthesis and have walking ability, and since the amputation cannot be reversed, distraction may be a useful strategy. Self-distraction requires the use of behaviors such as watching TV, exercising, reading, or engaging in pleasurable activities in order to distract oneself from the stressful event, that is, without directly confronting the situation. According to Boerner and Wang (2012), self-distraction strategy is a general category of "psychological self-regulation." Once again, prior research indicates that this strategy can be adaptive in certain circumstances (Kortte, Veiel, Batten \& Wegener, 2009; Kortte \& Wegener, 2004), reinforcing that the individual will alternate between strategies according to the demands of the rehabilitation process. In fact, the efficacy of a coping strategy may be appropriate in one context but not in another (Lazarus, 1993).

These results have important implications for clinical practice and future research. The intervention at the hospital should be directed primarily to individuals with an above-knee amputation who are at risk of having less satisfaction with life. Rehabilitation professionals should consider including a coping assessment measure in the standard assessment of this population and be aware of the differential role of coping strategies. In addition, health professionals should assess when a coping strategy has gone from a temporary coping strategy to a chronic and maladaptive response (Andersson \& Deighan, 2006; Sjödahl et al., 2004). Active and planned coping as well as religion, acceptance and humor were the coping strategies with greater impact on satisfaction with life. Therefore, intervention should consider including these coping strategies in psychosocial interventions, particularly coping skills training. Also, the demographic and clinical characteristics of individuals should be taken into account. In this sample, gender, age, marital status, the presence of RLP, prosthesis use and mobility were the demographic and clinical characteristics that influenced the use of a particular coping strategy, regardless of its "quality" whether functional or dysfunctional, problem or emotion cantered, approach or avoidant (Lazarus \& Folkman, 1984; Solberg Nes \& Segerstrom, 2006).

Another important finding was the high rate of individuals with RLP and PLP after four years (on average) of being amputated. Empirical evidence has shown how psychological interventions for pain are effective (Diers, Christmann, Koeppe, Ruff \& Flor, 2010; Ehde, Dillworth \& Turner, 2014; Jensen, Moore, Bockow, Ehde \& Engel, 2011). Therefore, amputated individuals should be referred to a pain consultation and/or a psychologist to develop coping strategies, as soon as possible, in order to avoid the development of chronic pain. In this sample, the probability of chronic pain is high, since almost $70 \%$ of amputees reported PLP. The duration of pain should therefore be addressed by the physician in all follow-up visits, after surgery. Finally, given that individuals, in this sample, will not be followed in the hospital during the entire rehabilitation process, it is important that support groups be made available to help social reintegration teaching the amputee effective coping strategies that consider the period of rehabilitation the individual is in. The perception of psychological well-being and satisfaction with life is likely to change throughout the process of adaptation to physical conditions/imitations, so it is important to help amputees develop coping mechanisms, over time, to solve problems (Livneh \& Antonak, 2005; Livneh \& Wilson, 2003). Although, this study has not focused on social support, it is important that the community reduces the environmental barriers, to make integration easier.

Future longitudinal studies should assess the intensity and interference of RLP and PLP as well as its duration, frequency and descriptors including the duration of pre-amputation pain specially in patients with Diabetes/DVP. The impact of positive variables such as optimism, resilience, mindfulness or the meaning of life should also be a topic of research in future studies with this population. 
This study has limitations that need to be acknowledged, such as sample size, the cross-sectional nature of the design and the sole inclusion of amputees who were in rehabilitation treatments, at the time of assessment, leaving those with longer amputation duration. Future studies should include individuals who have been amputated for a longer period of time as well as measures of functional limitation based on objective measures. In fact, effective measures for the quantification of mobility are essential to assess therapeutic interventions and translate research findings into clinical practice. In addition, since mobility is one of the most important predictors of satisfaction with life in this population, future research should also include the perspectives of informed proxies (e.g., family members), given that caregiverspecific support was found to be associated with higher levels of satisfaction with life, in this population (Brier, Williams, Turner et al., 2017).

\section{CONCLUSION}

Disability is a multidimensional phenomenon. When designing interventions for individuals with an amputation, besides clinical and physical characteristics (pain, level of functionality, characteristics of amputation), contextual influences, such as individual coping strategies shoud be considered. According to results, in order to promote satisfaction with life, besides physical rehabilitation, amputated individuals should go through a psychological assessment and intervention focused on the training of coping strategies associated with greater satisfaction with life, particularly those who were amputated in the past four years, and underwent an above-knee amputation.

\section{REFERENCES}

Amtmann, D., Morgan, S. J., Kim, J. \& Hafner, B. J. (2015). Health related profiles of people with lower limb loss. Archives of Physical Medicine and Rehabilitation, 96, 1474-1483.

Andersson, M. \& Deighan, F. (2006). Coping Strategies in Conjunction with Amputation: A literature study (C-level thesis 10 points). Karlstads University, Division for Health and Caring Sciences.

Aronow, W. S. (2007). Peripheral arterial disease in the elderly. Clinical Interventions in Aging, 2, 645-654.

Blace, N. P. (2012). Functional ability, participation in activities and life satisfaction of the older people. Asian Social Science, 8, 75-87.

Boerner, K. \& Wang, S. (2012). Goals with limited vision: A qualitative study of coping with vision-related goal interference in midlife. Clinical Rehabilitation, 26, 81-93.

Bowling, A. (1997). Measuring health: a review of quality of life measurement scales. London: Open University Press.

Brier, M. J., Williams, R. M., Turner, A. P., Henderson, A. W., Roepke, A. M, Norvell, D. C. et al. (2017). Quality of relationships with caregivers, depression, and life satisfaction after dysvascular lower extremity amputation. Archives of Physical and Medicine Rehabilitation, 99, 452-458.

Carver, C. S. (1997). You want to measure coping but your protocol's too long: consider the brief COPE. International Journal of Behavior Medicine, 4, 92-100.

Carver, C. S., Scheier, M. F. \& Weintraub, J. K. (1989). Assessing coping strategies: A theoretically based approach. Journal of Personality and Social Psychology, 56, 267-283.

Couture, M., Desrosiers, J. \& Caron, C. D. (2012). Coping with a lower limb amputation due to vascular disease in the hospital, rehabilitation, and home setting. ISRN, 1-9, https://doi.org/10.5402/2012/179878.
Couture, M., Desrosiers, J. \& Caron, C. D. (2011). Cognitive appraisal and perceived benefits of dysvascular lower limb amputation: A longitudinal study. Archives of Gerontology and Geriatrics, 52, 5-11.

Desmond, D. M. (2007). Coping, affective distress, and psychosocial adjustment among people with traumatic upper limb amputations. Journal of Psychosomatic Research, 62, 15-21.

Desmond, D. M. \& MacLachlan, M. (2006a). Coping strategies as predictors of psychosocial adaptation in a sample of elderly veterans with acquired lower limb amputations. Social Science Medicine, 62, 208-216.

Desmond, D. M. \& MacLachlan, M. (2006b). Affective distress and amputation-related pain among older men with long-term, traumatic limb amputations. Journal of Pain and Symptom Management, 31, 362-368.

Dias, M. A. (2006). Qualidade de vida relacionada com a saúde e satisfação com a vida: Um estudo em pacientes amputados do membro inferior [Master Thesis]. [Health related quality of life and satisfaction with life: a study in patients with a lower limb amputation]. Faculdade de Ciências do Desporto e de Educação Física da Universidade do Porto, Portugal.

Diener, E., Emmons, R., Larsen, R. \& Griffiin, S. (1985). The satisfaction with life scale. Journal of Personality Assessment, 49, 71-75.

Diers, M., Christmann, C., Koeppe, C., Ruff, M. \& Flor, H. (2010). Mirrored, imagined and executed movements differentially activate sensorimotor cortex in amputees with and without phantom limb pain. Pain, 149, 296-304.

Dubey, A. \& Agarwal, A. (2007). Coping strategies and life satisfaction: Chronically ill patients' perspectives. Journal of the Indian Academy of Applied Psychology, 33, 161-168.

Dunn, D. S. (1996). Well-being following amputation: Salutary effects of positive meaning, optimism, and control. Rehabilitation Psychology, 41, 285-302.

Dunne, S., Coffey, L., Gallagher, P. \& Desmond, D. (2014). "If I can do it will do it, if I can't, I can't": A study of adaptative self-regulatory strategies following lower limb amputation. Disability \& Rehabilitation, 36, 1990-1997.

Ehde, D. M., Czerniecki, J. M., Smith, D. G., Campbell, K. M., Edwards, W. T., Jensen, M. P. et al. (2001). Chronic phantom sensations, phantom pain, residual limb pain, and other regional pain after lower limb amputation. Archives of Physical and Medicine Rehabilitation, 81, 1039-1044.

Ehde, D. M., Dillworth, T. M. \& Turner, A. (2014). Cognitive-behavioral therapy for individuals with chronic pain. Efficacy, Innovations, and Directions for Research, 69, 153-166.

Eurofound (2012). 3rd European Quality of Life Survey - quality of life in Europe: Impacts of the crisis. Retrieved 20 August 2017 from http://ec.europa.eu/eurostat/statistics-explained/index.php/Quality_ of_life_indicators_-_overall_experience_of_life.

Foell, J. \& Flor, H. (2011). Phantom Limb Pain. In R. J. Moore (Ed.), Handbook of pain and palliative care (pp. 417-430). New York: Springer.

Gallagher, P. \& MacLachlan, M. (2000). Positive meaning in amputation and thoughts about the amputated limb. Journal of Prosthetics \& Orthotics International, 24, 196-204.

Gallagher, P. \& Maclachlan, M. (2001). Adjustment to an artificial limb: A qualitative perspective. Journal of Health Psychology, 6, 85-100.

Hill, A., Niven, C. A. \& Knussen, C. (1995). The role of coping in adjustment to phantom limb pain. Pain, 62, 79-86.

International Working Group on the Diabetic Foot (2007). International consensus on the diabetic foot \& practical guidelines on the management and prevention of the diabetic foot. [DVD].

Jackson, M. \& Simpson, K. (2004). Pain after amputation. British Journal of Anaesthesia, 4, 20-23.

Jensen, M. P., Moore, M. R., Bockow, T. B., Ehde, D. M. \& Engel, J. M. (2011). Psychosocial factors and adjustment to chronic pain in persons with physical disabilities: A systematic review. Archives of Physical and Medicine Rehabilitation, 92, 146-160.

Kohler, R. E., Tomlinson, J., Chilunjika, T. E., Young, S., Hosseinipour, M. \& Lee, C. N. (2017). "Life is at a standstill". Quality of life after 
lower extremity trauma in Malawi. Quality of Life Research, 26, 1027-1035.

Kortte, K. B., Veiel, L., Batten, S. V. \& Wegener, S. T. (2009). Measuring avoidance in medical rehabilitation. Rehabilitation Psychology, 54, 91-98.

Kortte, K. B. \& Wegener, S. T. (2004). Denial of illness in medical rehabilitation populations: Theory, research, and definition. Rehabilitation Psychology, 49, 187-199.

Kroll, C. (2011). Different things make different people happy: Examining social capital and subjective well-being by gender and parental status. Social Indicators Research, 104, 157-177.

Lazarus, R. S. (1993). Coping theory and research: Past, present, and future. Psychosomatic Medicine, 55, 234-247.

Lazarus, R. S. \& Folkman, S. (1984). Stress, appraisal, and coping. New York: Springer.

Livneh, H. \& Antonak, R. F. (1997). Psychosocial adaptation to chronic illness and disability. Gaithersburg, MD: Aspen Publishers.

Livneh, H. \& Antonak, R. F. (2005). Psychosocial adaptation to chronic illness and disability: A primer for counsellors. Journal of Counseling and Development, 83, 12-20.

Livneh, H., Antonak, R. F. \& Gerhardt, J. (1999). Psychosocial adaptation to amputation: The role of sociodemographic variables, disability related factors and coping strategies. International Journal of Rehabilitation Research, 22, 21-31.

Livneh, H. \& Wilson, L. M. (2003). Coping strategies as predictors and mediators of disability-related variables and psychosocial adaptation: An exploratory investigation. Rehabilitation Counseling Bulletin, 46, 194-208.

Maes, S., Leventhal, H. \& Ridder, D. (1996). Coping with chronic diseases. In M. Zeidner \& N. Endler (Eds.), Handbook of Coping: Theory, Research, Applications (pp. 221-251). New York: Wiley.

Marshall, M., Helmes, E. \& Deathe, A. B. (1992). A comparison of psychosocial functioning and personality in amputee and chronic pain populations. Clinical Journal of Pain, 8, 351-357.

Neil, M. J. E. (2015). Pain after amputation. Oxford: BJA Education.

Neto, F., Barros, J. \& Barros, A. (1990). Satisfação com a vida. In L. Almeida, R. Santiago, P. Silva, O. Caetano \& J. Marques (Eds.), A acção educativa: Análise psico-social (pp. 91-100). [Satisfaction with life. In Educational action: Psycho-social analysis]. Leiria, Portugal: ESEL/APPORT.

Ostile, K., Magnus, P., Skjeldal, O. H., Garfelt, B. \& Tambs, K. (2010). Mental health and satisfaction with life among upper limb amputees: A Norwegian population-based survey comparing adult acquired major upper limb amputees with a control group. Disability and Rehabilitation, 33, 1594-1607.

Pais-Ribeiro, J. L. \& Rodrigues, A. P. (2004). Questões acerca do coping: A propósito do estudo de adaptação do Brief COPE [Questions about coping: Regarding the study of adaptation of Brief COPE]. Psicologia, Saúde \& Doenças, 5, 3-15.

Peirano, A. H. \& Franz, R. W. (2012). Spirituality and quality of life in limb amputees. International Journal of Angiology, 2, 47-52.

Penn-Barwell, J. G. (2011). Outcomes in lower limb amputation following trauma: A systematic review and meta-analysis. Injury, 42, 1474-1479.
Portuguese Society of Diabetes (2016). Diabetes: Factos e números 2015: Relatório anual do observatório Nacional da Diabetes [Diabetes: Facts and numbers 2015: Annual report from Diabetes National Observatory]. Retrieved 20 August 2017 from http://www.spd.pt/ima ges/bolsas/dfn2015.pdf.

Quigley, M. \& Dillon, M. (2014). Quality of life in persons with partial foot or transtibial amputation: A systematic review. Prosthetics and Orthotics International, 40, 1-13.

Ramsey, S. D., Newton, K., Blough, D., McCulloch, D. K., Sandhu, N., Reiber, G. E. et al. (1999). Incidence, outcomes and cost of foot ulcers in patients with diabetes. Diabetes Care, 22, 382-387.

Remes, L., Isoaho, R., Vahlberg, T., Viitanen, M., Koskenvuo, M. \& Rautava, P. (2010). Quality of life three years after major lower extremity amputation due to peripheral arterial disease. Aging Clinical and Experimental Research, 22, 395-405.

Sansam, K., Neumann, V., O'Connor, R. \& Bhakta, B. (2009). Predicting walking ability following lower limb amputation: A systematic review of the literature. Journal of Rehabilitation Medicine, 41, 593-603.

Sinha, R. \& van den Heuvel, W. J. (2011). A systematic literature review of quality of life in lower limb amputees. Disability and Rehabilitation, 33, 883-899.

Sinha, R., van den Heuvel, W. J. \& Arokiasamy, P. (2011). Factors affecting quality of life in lower limb amputees. Prosthetics Orthotics International, 35, 90-96.

Sjödahl, C., Gard, G. \& Jarnlo, G. B. (2004). Coping after trans-femoral amputation due to trauma or tumour: a phenomenological approach. Disability and Rehabilitation, 26, 851-861.

Solberg Nes, L. \& Segerstrom, S. C. (2006). Dispositional optimism and coping: A metaanalytic review. Personality and Social Psychology Review, 10, 235-251.

Tuncay, T. \& Musabak, I. (2015). Problem-focused coping strategies predict posttraumatic growth in veterans with lower limb amputations. Journal of Social Service Research, 18, 11-22.

Unwin, N. (2000). Epidemiology of lower extremity amputation in centres in Europe, North America and East Asia. British Journal of Surgery, 87, 328-337.

Unwin, J., Kacperek, L. \& Clarke, C. (2009). A prospective study of positive adjustment to lower limb amputation. Clinical Rehabilitation, 23, 1044-105.

van der Hulst, M., Vollenbroek-Utten, M. M., Schreurs, K. M., Rietman, J. S. \& Hermens, H. J. (2010). Relationships between coping strategies and lumbar muscle activity in subjects with chronic low back pain. European Journal of Pain, 14, 640-647.

Varma, P., Stineman, M. G. \& Dillingham, T. R. (2014). Epidemiology of limb loss. Physical Medicine Rehabilitation Clinics of North America, $25,1-8$.

Wegener, S. T., Mackenzie, E. J., Ephraim, P., Ehde, D. \& Williams, R. (2009). Self-management improves outcomes in persons with limb loss. Archives of Physical Medicine and Rehabilitation, 90, 373-380.

Received 12 September 2017, accepted 8 February 2018 